\title{
Diagnosis and treatment of biliary malignancies: biopsy, cytology, cholangioscopy and stenting
}

\author{
Viveksandeep Thoguluva Chandrasekar, Douglas Faigel \\ Mayo Clinic, Scottsdale, AZ 85259, USA. \\ Correspondence to: Prof. Douglas Faigel, Mayo Clinic, 13400 E Shea Blvd, Scottsdale, Arizona 85259, USA. E-mail: \\ faigel.douglas@mayo.edu \\ How to cite this article: Chandrasekar VT, Faigel D. Diagnosis and treatment of biliary malignancies: biopsy, cytology, \\ cholangioscopy and stenting. Mini-invasive Surg 2021;5:33. https://dx.doi.org/10.20517/2574-1225.2021.12
}

Received: 2 Feb 2021 First Decision: 8 May 2021 Revised: 18 May 2021 Accepted: 11 Jun 2021 Available online: 17 Jun 2021

Academic Editor: Jean-François Rey Copy Editor: Xi-Jun Chen Production Editor: Xi-Jun Chen

\begin{abstract}
Biliary tract malignancies include cancers of the intra-hepatic and extra-hepatic bile ducts. Cholangiocarcinoma is the predominant biliary tract malignancy with nearly $60 \%$ of them occurring in the peri-hilar region. They can present with biliary strictures causing jaundice but can be insidious and present late in their clinical course. Recent advances in imaging and other diagnostic modalities help in the earlier identification of these tumors. Diagnosis should be suspected in anyone presenting with jaundice with evidence of biliary ductal dilatation or in patients with primary sclerosing cholangitis with worsening clinical status. The diagnostic approach consists of obtaining tumor markers, mainly CA 19-9, imaging modalities which include computed tomography and/or magnetic resonance imaging to establish the level of biliary obstruction and presence or absence of mass. Tissue sampling is performed with endoscopic retrograde cholangiopancreatography (ERCP) guided cytology and biopsies and with endoscopic ultrasound (EUS) if a mass is visible on imaging. Indeterminate strictures after initial biopsies could be further evaluated by cholangioscopy directed biopsies. Treatment for resectable and distal bile duct cancers involves surgical referral, but palliative biliary drainage is the key for unresectable cancers. Metal stents are generally preferred for distal cancers and plastic stents for proximal cancers. EUS guided biliary drainage can be an alternative approach in patients with failed ERCP.
\end{abstract}

Keywords: Cholangiocarcinoma, malignant biliary strictures, endoscopic retrograde cholangiopancreatography, stent, endoscopic ultrasound 


\section{INTRODUCTION}

Biliary tract malignancies are broadly classified into three categories: (1) intra-hepatic biliary tract cancers; (2) cancer of the extra-hepatic biliary tract and the gall bladder; and (3) ampulla of vater cancer. Cholangiocarcinoma (CCA) includes tumors of the intra-hepatic bile ducts, peri-hilar and extra-hepatic bile ducts ${ }^{[1]}$. Cancers in the distal bile duct can present with biliary strictures due to CCA, pancreatic head cancers or cancer of the ampulla of vater and they behave clinically similar, thus being broadly categorized as peri-ampullary tumors. Among CCAs, about 5\%-10\% are intra-hepatic and about $60 \%$ of the extrahepatic CCAs are in the peri-hilar region, classified as the Klatskin tumors ${ }^{[2]}$ [Table 1]. CCA is the most common biliary tract malignancy but accounts for less than $2 \%$ of all cancers ${ }^{[3]}$. It is often the most difficult to diagnose among all gastrointestinal cancers with a dismal 5 -year survival rate of about $5 \%{ }^{[4]}$. Risk factors for CCA include primary sclerosing cholangitis (PSC), choledochal cyst, parasitic infections like Clonorchis, exposure to thorotrast, hepatolithiasis and familial polyposis but the majority occur sporadically $\mathrm{y}^{[5]}$. Malignant biliary strictures can present with symptoms and signs due to obstruction of the bile ducts including abdominal pain in the right upper quadrant, jaundice, fever or chills due to cholangitis, but they can also be non-specific. They are often insidious in growth and can present late in their clinical course with a poor prognosis. With the advent of advanced imaging technologies, biliary tract malignancies are diagnosed at an earlier stage, offering a potential surgical cure or liver transplant options for patients. Despite all this, only about $20 \%$ of malignant biliary obstructions (MBO) are resectable at the time of diagnosis ${ }^{[6]}$. This review will address the diagnostic steps for evaluation of MBO due to biliary etiology, tissue sampling methods and the management strategies for biliary drainage, with a predominant focus on CCA.

\section{Diagnostic approach}

Diagnosis of a biliary malignancy should be suspected in a patient who presents with symptoms and signs of biliary obstruction, including jaundice, abdominal pain, abnormal liver enzymes with mainly a cholestatic pattern or evidence of biliary ductal dilatation on imaging. Presence of an intra-hepatic mass on imaging warrants further investigation to rule out CCA. In patients with PSC, any deterioration in clinical status with worsening jaundice or weight loss, with or without the presence of biliary ductal dilatation should be further investigated to look for the presence of any dominant stricture and evaluated for CCA, especially in the setting of wall thickening of the bile duct.

The approach for diagnosis depends on the location of the suspected lesion, if it is intra-hepatic, peri-hilar or in the distal biliary tract. Once a biliary tumor is suspected, the patient should undergo further testing with tumor markers, imaging studies and endoscopic or percutaneous procedures for sampling to establish a diagnosis. A tissue diagnosis is generally necessary prior to any surgical planning, documentation prior to non-operative treatment modalities like chemoradiation and especially in indeterminate strictures, where establishing a diagnosis will change the management. Distal biliary tumors can cause both intra- and extrahepatic biliary ductal dilatation while peri-hilar tumors cause intrahepatic ductal dilatation with normal extrahepatic ducts.

\section{CROSS-SECTIONAL IMAGING STUDIES Ultrasonography}

Trans-abdominal ultrasonography (US) is often the first imaging modality obtained for any patient with abnormal liver enzymes with jaundice or right upper quadrant abdominal pain. US can provide information on biliary ductal dilatation with a possible level of obstruction, presence of gall stones or common bile duct (CBD) stones and intra-hepatic CCA as masses with mixed echogenicity. Direct visualization of a mass in the extra-hepatic bile duct is usually unlikely with US. Albu et al. ${ }^{[7]}$ in their series of 124 patients with extra- 
Classification of CCA based on anatomical location

1. Intra-hepatic cholangiocarcinoma

2. Extra-hepatic cholangiocarcinoma (up to second order bile ducts)

(a) Peri-hilar CCA

(b) Distal CCA

Bismuth-Corlette classification of peri-hilar CCA

Type 1: Involving common hepatic duct below the confluence of right and left hepatic ducts

Type 2: Involving the confluence of right and left hepatic ducts

Type 3a: Involving the confluence and extending into right hepatic duct

Type $3 \mathrm{~b}$ : Involving the confluence and extending into left hepatic duct

Type 4: Involving confluence and extending into both right and left hepatic duct/ multifocal

Classification of CCA based on morphological type:

1. Peri-ductal infiltrating (most common)

2. Mass-forming or exophytic

3. Intraductal papillary

CCA: Cholangiocarcinoma

hepatic CCA showed the sensitivity in identifying distal bile duct tumor to be low at 33\% while hilar tumors were higher at $86 \%$. Although it is the first test usually performed, further imaging studies are usually required.

\section{Multi-detector computed tomography}

Multi-detector computed tomography (MDCT) is the most commonly used modality and can provide information on intra-hepatic tumors, level of biliary obstruction with more detailed information on strictures compared to US, potentially distinguishing benign from malignant strictures. It also provides information on vascular and lymph node involvement and sites of metastasis ${ }^{[8]}$. A meta-analysis of 16 studies by Ruys et al. ${ }^{[9]}$ demonstrated an accuracy of $86 \%$ for detecting the ductal involvement of the tumor. The sensitivities for evaluation of hepatic artery, portal vein and lymph node involvement were $83 \%, 89 \%$ and $61 \%$, respectively with specificities of $93 \%, 92 \%$ and $88 \%$, respectively ${ }^{[10]}$.

\section{Magnetic resonance imaging/magnetic resonance cholangio-pancreatogram}

Magnetic resonance imaging/magnetic resonance cholangio-pancreatogram (MRI/MRCP) has the advantage of providing a three-dimensional image of the biliary system and vascular structures ${ }^{[11]}$. The information on the extent of the tumor/stricture and resectability has been comparable to MDCT and cholangiography. Zhang et al. ${ }^{[10]}$ in their series showed comparable sensitivities for assessment of resectability for MRI and MDCT of $95 \%$ and $94 \%$ with a specificity of $69 \%$ and $71 \%$, respectively. In a study comparing endoscopic retrograde cholangiopancreatography (ERCP) and MRCP for evaluation of malignant peri-hilar tumors, both modalities identified all the obstructions but MRCP was superior in defining the extent of the tumor ${ }^{[12]}$. If MRI/MRCP is to be performed, it should be obtained prior to any endoscopic procedures with drainage, since it makes it difficult to evaluate the biliary tree after decompression with stents. MRI/MRCP is useful prior to ERCP for treatment planning.

\section{Positron emission tomography}

The role of positron emission tomography (PET) scan is mainly to detect occult distant metastasis which can change the surgical course in about $20 \%-25 \%$ of the patients ${ }^{[13]}$. It could also play a role in identifying CCA in the setting of PSC or indeterminate strictures ${ }^{[14]}$. It is not routinely used for staging purposes in CCA but can provide insightful information in the select group of patients. Prior studies have shown its utility in highlighting the "hot spots" in such cases, thus potentially aiding in the diagnosis of CCA, although no clear standardized uptake value (SUV) thresholds have been defined for differentiation between benign and malignant lesions. 


\section{Tumor markers}

Carbohydrate antigen 19-9 (CA 19-9) and carcinoembryonic antigen (CEA) have been studied for the diagnosis of biliary tumors. Although they may be of some diagnostic value, they are not specific for the diagnosis of biliary tumors, especially since they can also be elevated in some benign conditions ${ }^{[15-17]}$. The role of CA 19-9 in patients with PSC is particularly helpful and can help with the diagnosis of CCA, especially if there is a sudden increase in the level ${ }^{[18]}$. Studies on CA 19-9 have shown wide variations in sensitivity (46\%-90\%) and specificity (54\%-98\%) $)^{[19-21]}$. It can be elevated in benign conditions like cholangitis, biliary obstruction due to other reasons, liver cirrhosis and other malignancies like pancreatic cancer. Kim et al. ${ }^{[17]}$ in their analysis suggested a cut-off value of $37 \mathrm{U} / \mathrm{mL}$ with a sensitivity of $78 \%$ and specificity of $83 \%$ for the diagnosis of pancreatobiliary malignancies but dropped to $74 \%$ and $42 \%$ respectively in the presence of cholangitis/cholestasis. CA 19-9 assay can be used for surveillance of CCA in patients with PSC. Levy et al. ${ }^{[21]}$ used a cut-off of $129 \mathrm{U} / \mathrm{mL}$ and demonstrated a sensitivity of $79 \%$ and specificity of $99 \%$ for the diagnosis of CCA, but the positive predictive value was lower at 57\%. CEA has demonstrated lower sensitivity and specificity compared to CA 19-9 and can be elevated in other malignancies. If levels of either marker are increased, it may be used to monitor response to treatment in the setting of CCA.

\section{TISSUE SAMPLING TECHNIQUES}

\section{Endoscopic retrograde cholangiopancreatography}

ERCP is still considered the gold standard for biliary imaging with the ability to obtain tissue sampling for diagnosis. Due to recent advances in imaging modalities with CT and MRI/ MRCP, studies have shown comparable diagnostic accuracy with $\mathrm{ERCP}^{[22]}$. ERCP is useful in the diagnosis of ECCA and peri-hilar CCA. Cholangiograms reveal a stricture in the biliary tract with or without upstream biliary ductal dilatation. Malignant strictures usually appear as long segments with irregularity and asymmetry with shelving [Figure 1] ${ }^{[23]}$. Histopathological diagnosis could be obtained with ERCP with one of the three modalities: (1) brush cytology; (2) aspiration of biliary fluid; and (3) biopsy with endobiliary forceps. The sensitivity of these techniques varies when performed individually versus in combination and carries a specificity of almost $100 \%$ [Table 2].

\section{Cytology and aspiration}

Bile duct brushings are commonly performed to differentiate benign from malignant strictures. Several studies have shown variable sensitivity rates from $23 \%-86 \%{ }^{[24]}$. Kurzawinski et al.$^{[25]}$ in the prospective study of 100 patients with biliary strictures reported a 33\% sensitivity for detection of CCA. A meta-analysis of more than 1500 patients by Burnett et al. ${ }^{[26]}$ reported a sensitivity of $42 \%$. Frequently cytology is combined with fluorescent in situ hybridization (FISH) or mutation profiling (MP) to increase sensitivity. Kushnir et al. ${ }^{[27]}$ demonstrated in their study that sensitivity for cytology alone was $26 \%$ but when combined with FISH and MP, it was $44 \%$ and 56\% respectively. When all 3 modalities were combined it was $66 \%$. Dudley et al. ${ }^{[28]}$ in their study combined next generation sequencing with cytology improving their sensitivity from $67 \%$ to $85 \%$.

Sugimoto et al. ${ }^{[29]}$ demonstrated that aspiration of bile in 76 patients with biliary strictures demonstrated a sensitivity of $32 \%$ for the diagnosis of biliary cancers but the sensitivity improved to $70 \%$ when aspiration was performed after biliary brushings. The sensitivity also improved with the aspiration of a higher amount of fluid, protruding type tumors compared to flat type and for tumor with longer stricture segments. The Presence of a desmoplastic reaction and inflammatory changes can decrease the sensitivity.

\section{Biliary forceps biopsy}

Endoluminal biopsy using biliary forceps is technically more challenging compared to brushings and generally requires a sphincterotomy. It can also be difficult to perform in narrow bile ducts and tumors 
Table 2. Sensitivity and specificity of various modalities in the diagnosis of malignant biliary strictures

\begin{tabular}{lll}
\hline & Sensitivity & Specificity \\
\hline ERCP with brush cytology & $23 \%-66 \%$ & $99 \%-100 \%$ \\
ERCP with biliary fluid aspiration & $6 \%-36 \%$ & NA \\
ERCP with biliary forceps biopsy & $45 \%-81 \%$ & $99 \%-100 \%$ \\
Intraductal ultrasound & $88 \%-94 \%$ & $86 \%-90 \%$ \\
Endoscopic ultrasound & $43 \%-90 \%$ & $78 \%-96 \%$ \\
Spyglass Cholangioscopy & $64 \%-94 \%$ & $95 \%-100 \%$ \\
\hline
\end{tabular}

ERCP: Endoscopic retrograde cholangiopancreatography.
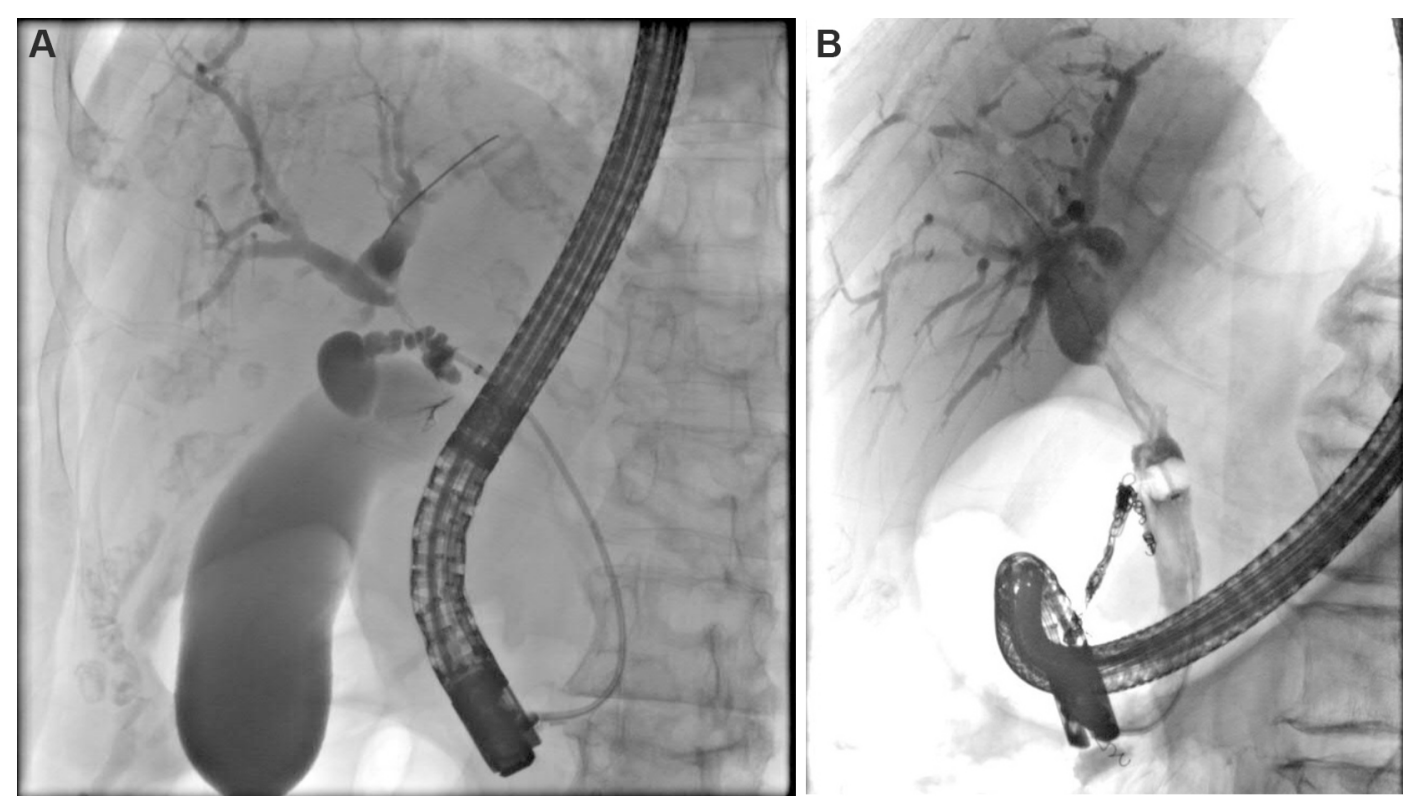

Figure 1. Endoscopic retrograde pancreatography image demonstrating (A) Hilar stricture in a patient with cholangiocarcinoma and (B) Stricture in the common hepatic duct in a patient with cholangiocarcinoma.

higher up in the biliary tree and complications related to tumor bleeding and perforation should be kept in mind. Studies have shown varying sensitivity between $50 \%$ and $81 \%$ for the diagnosis of biliary cancers ${ }^{[30,31]}$. Chen et al. ${ }^{[32]}$ demonstrated a sensitivity of $53.8 \%$ for the diagnosis of pancreato-biliary malignancy from biliary strictures, with higher sensitivity for CCA when compared to pancreatic cancer ( $74 \% v s$. 29\%). The exact number of biopsies required for diagnosis has been reported to be variable between 1 and 6 in several studies. Tamada et al. ${ }^{[30]}$ showed that infiltrating type biliary malignancies required more bites while 3 biopsies were sufficient to increase the sensitivity to near 100\% for papillary type CCA. In order to improve the sensitivity, the combination of brushings along with biliary forceps biopsy has shown better results. A meta-analysis of 9 studies showed the sensitivity for brushings and biopsies to be $45 \%$ and $48 \%$ respectively but their combination improved it to $59 \%{ }^{[33]}$.

\section{Intraductal ultrasonography}

Intraductal ultrasonography (IDUS) consists of high-frequency catheter probes that can be introduced into the CBD over a guidewire most often during ERCP. It is used for the detection of biliary tumors with local staging. There are usually three layers visible on IDUS: an inner hyperechoic layer corresponding to the mucosa, a middle hypoechoic layer of muscle fibers and an outer hyperechoic layer of connective tissue ${ }^{[34]}$. The presence of a hypoechoic mass with disruption of normal ultrasonographic pattern and irregular 
margins and invasion of the tumor into surrounding tissues are some of the features of malignancy ${ }^{[35]}$. Presence of a sessile intra- or extra-ductal tumor and the size of the tumor more than $10 \mathrm{~mm}$ were also suggested as high-risk features by Tamada et al. ${ }^{[36]}$. Studies have also shown IDUS to demonstrate higher sensitivity and specificity when compared to endoscopic ultrasound (EUS) while similar sensitivity and almost similar specificity compared to ERCP guided tissue biopsies, in distinguishing benign and malignant strictures $^{[37,38]}$. IDUS can also be useful in guiding biopsies, as the presence of a sessile tumor or high-risk features on IDUS resulted in higher rates of positive sampling. IDUS can also provide information regarding the longitudinal spread of the tumor along the bile duct, depth of tumor invasion and vascular invasion ${ }^{[39]}$. Diagnostic accuracy for hepatic artery and portal vein invasion has been reported to be between $86 \%$ to $100 \%$ in studies ${ }^{[39]}$. The drawback of IDUS despite the above advantages is that tissue sampling cannot be obtained, availability mainly in only tertiary care centers and teaching hospitals and requires sufficient expertise to interpret the findings.

\section{Endoscopic ultrasound}

EUS can be used in the diagnosis and staging of biliary tract cancers by being able to detect masses that can appear hypoechoic, biliary ductal dilatation and evaluation of the vasculature and lymph nodes for involvement with the tumor ${ }^{[40]}$ [Figure $2 \mathrm{~A}$ ]. Studies have shown high rates of sensitivity and specificity for detection of malignant strictures up to $80 \%$ with detection of distal cancers up to $100 \%$ and lower rates for proximal CCAs $s^{[41,42]}$. Linear EUS scopes provide the ability to perform fine-needle aspiration (FNA), thus improving the diagnostic accuracy [Figure 2B]. With FNA, sensitivity ranging from $43 \%-90 \%$ and specificity ranging from $80 \%-100 \%$ have been reported, with higher rates in distal $\mathrm{CCA}^{[43]}$. Comparing EUS-FNA with ERCP for diagnosis, studies have shown mixed results with some favoring EUS-FNA and others showing ERCP with biopsies to be superior ${ }^{[4-46]}$. But EUS-FNA with ERCP and brushings during the same session has demonstrated superiority compared to EUS-FNA alone ${ }^{[46]}$. There are some drawbacks to remember while performing and interpreting the results of EUS-FNA. Studies have shown low negative predictive values ranging from $30 \%$ to $65 \%$ and hence a negative result does not rule out malignancy in the appropriate clinical setting. An additional complication with EUS-FNA not seen with endo-biliary sampling is tumor seeding after FNA, especially in proximal biliary tumors involving the hilum, as they can lead to peritoneal metastasis. Peritoneal metastasis rates up to $80 \%$ have been reported after EUS-FNA sampling ${ }^{[47,48]}$. Liver transplantation protocols usually preclude these patients from undergoing transplantation if FNA is performed pre-operatively for hilar malignancies. The concern for tumor seeding is lower with distal biliary strictures and hence EUS-FNA is not a contraindication in such cases.

Despite the use of the above-mentioned techniques, false-negative results are still possible. While a positive result can confirm a diagnosis of malignancy, a negative result does not necessarily rule it out, especially if the pre-test probability is high and these are labelled "indeterminate strictures". They are defined as strictures with no obvious mass on imaging and cannot be reliably differentiated as benign or malignant, despite workup with ERCP and tissue sampling as described above. Furthermore, the diagnostic yield for strictures due to various etiologies is different, with higher rates for CCA compared to other peri-ductal etiologies like pancreatic cancer and gall bladder cancer, thus adding more confusion in clearly defining these strictures. Surgical exploration can be considered in such cases but recently the use of direct cholangioscopy guided biopsy has led to a reduction in the need for surgeries and provide the ability for direct visualization of these strictures. Despite all the workup, if the concern for malignancy remains high, such patients can be referred to surgery for further exploration.

\section{Cholangioscopy}

Digital single operator cholangioscope (DSOC, SpyGlass, Boston Scientific Inc. Massachusetts, USA) consists of a single disposable 10.5 Fr scope, which can be passed through a duodenoscope. This scope can 

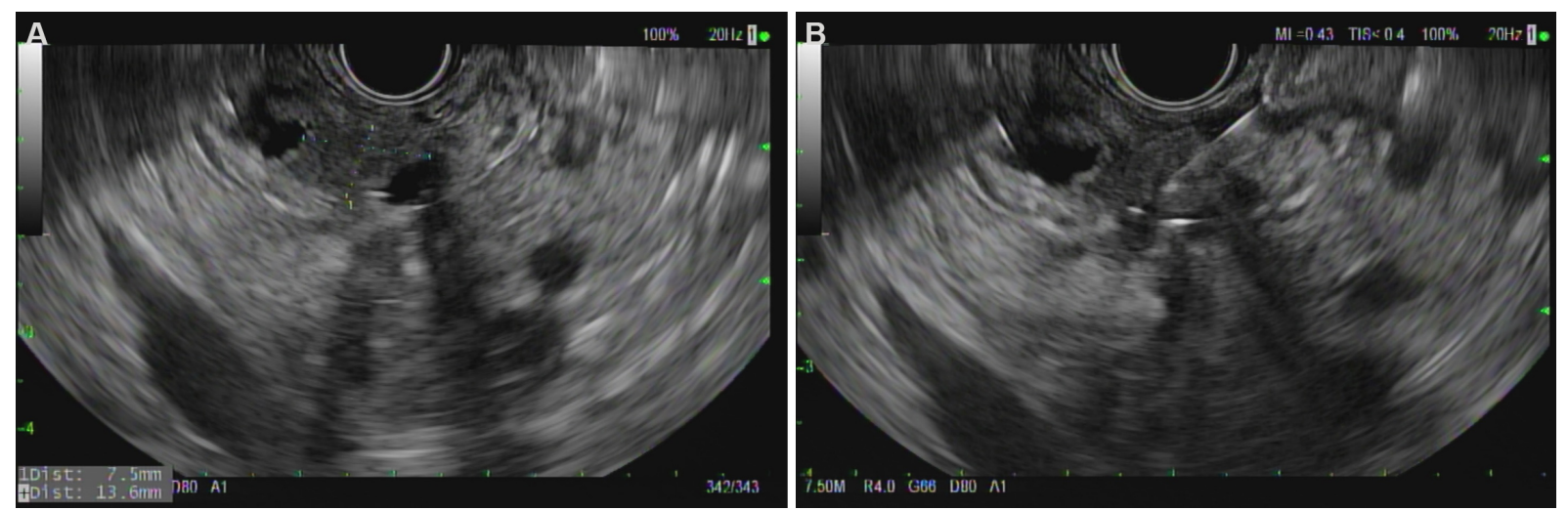

Figure 2. Endoscopic ultrasound demonstrating (A) mass in the distal bile duct in a patient with cholangiocarcinoma (B) fine needle aspiration of the mass.

be passed over a guidewire into the bile duct enabling direct visualization, with the ability to perform suction, irrigation and biopsies with specialized forceps (SpyBite) ${ }^{[49]}$. The presence of an obvious mass (nodular or papillary), abnormal blood vessels which are dilated and tortuous, irregularity in the surface can be predictive of malignancy [Figure 3]. Pereira et al. ${ }^{[50]}$ in their retrospective study showed a visual accuracy of $95.1 \%$ for the diagnosis of malignancy with a sensitivity of $100 \%$ and specificity of $89.5 \%$. The SpyBite's accuracy was $80.5 \%$ with a sensitivity of $64 \%$ and specificity of $100 \%$. Evaluation by cholangioscopy changed the Bismuth classification in $42 \%$ of patients compared to imaging prior to the study. Other studies have shown a higher sensitivity for SpyBite up to $86 \%{ }^{[51,52]}$. Varadarajalu et al.$^{[53]}$ in their retrospective study of 31 patients with indeterminate biliary strictures, demonstrated that the sensitivity could be increased to $94 \%$ using rapid on-site examination with cytology ${ }^{[54]}$. A randomized controlled trial (RCT) by Bang et al. ${ }^{[55]}$ comparing patients undergoing cholangioscopy guided biopsies for indeterminate biliary strictures with onsite vs offsite processing techniques demonstrated similar diagnostic accuracy, sensitivity and specificity for both techniques, but the median number of biopsies to establish diagnosis was lower in the onsite group.

Studies have reported higher morbidity and rate of complications with cholangioscopy with up to five times higher rates of cholangitis in these patients. A meta-analysis including more than 2000 patients reported an adverse event rate of $7 \%$ with a serious adverse event rate of $1 \%{ }^{[56]}$. The role of direct cholangioscopy in the diagnostic algorithm [Figure 4] for biliary cancers is still being investigated given the complexity, availability, procedural duration, costs, and complications. It is a valuable tool for the investigation of indeterminate biliary strictures with prior ERCPs inconclusive for malignancy when the clinical suspicion is high.

\section{Treatment}

Therapy for malignant biliary strictures depends primarily on the level of obstruction (hilar $v s$. distal) and if the malignancy is resectable or not. The treatment goal for biliary malignancies is providing a surgical cure if the cancer is resectable or promoting biliary drainage in unresectable cancers. With advances in the field of interventional endoscopy and ERCP, biliary drainage can be achieved in most patients thus improving the quality of life.

\section{Resectable cancers}

Hyperbilirubinemia was thought to be associated with poorer surgical outcomes and hence earlier studies focused on biliary drainage pre-operatively to reduce the risk by the placement of biliary stents endoscopically ${ }^{[57]}$. More recent data in the form of RCT have not shown any benefit in mortality for patients 


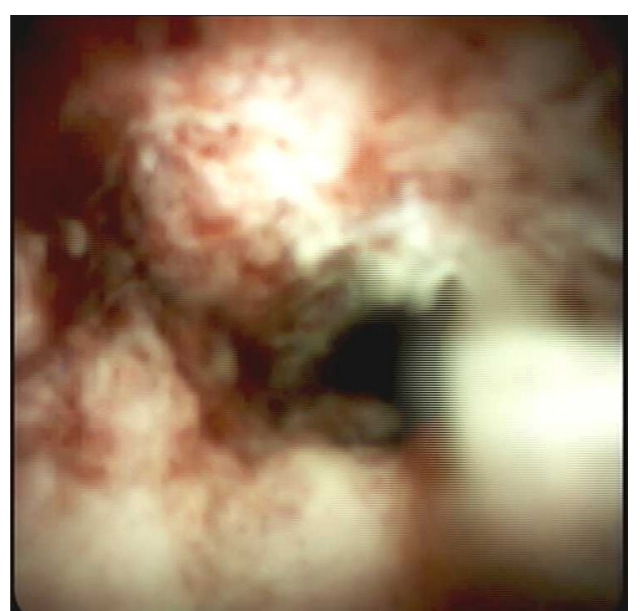

Figure 3. Spyglass cholangioscopy demonstrating infiltrative mass in the bile duct with abnormal vasculature and friable mucosa in a patient with cholangiocarcinoma.

who underwent pre-operative drainage, but also demonstrated an increase in complications postoperatively for these patient ${ }^{[58,59]}$. Specifically, cholangitis is a clinical concern as placement of a stent for biliary drainage would increase the risk of infection in an otherwise sterile field without an ERCP. Another RCT comparing endoscopic and percutaneous transhepatic biliary drainage (PTBD) for pre-operative biliary drainage was terminated early due to higher mortality in the PTBD arm (41\%) compared to endoscopic drainage $(11 \%)^{[60]}$. A meta-analysis by Fang et al. ${ }^{[61]}$ also demonstrated no mortality benefit for pre-operative biliary drainage. For distal strictures due to pancreatic cancer and asymptomatic hyperbilirubinemia, the American Society for Gastrointestinal Endoscopy recommends against routine preoperative biliary drainage. Endoscopic biliary drainage pre-operatively should be reserved for patients who have cholangitis, significant symptoms due to obstruction like pruritis and for those patients undergoing neo-adjuvant chemotherapy in order to bring the higher bilirubin levels down prior to chemotherapy ${ }^{[62]}$. It is also ideal to delay the surgery a few weeks after biliary drainage if able, for the hepatic function to normalize, to improve the post-operative outcomes. For distal cancers, pancreaticoduodenectomy or Whipple's procedure is the treatment of choice. For intra-hepatic tumors, resection of the tumor with negative margins with or without portal lymphadenectomy is generally performed. For perihilar tumors, hepatic lobectomy or trisectionectomy along with resection of the extra-hepatic bile duct and gall bladder with a Roux-en-Y hepatico-jejunostomy is performed.

\section{Unresectable cancers}

Most CCA, close to $70 \%-80 \%$, are unresectable at the time of diagnosis and endoscopic procedures in these patients are mainly palliative to decompress the biliary tract and improve quality of life but have no mortality benefit. The endoscopic options available are ERCP with biliary stenting which is the primary palliative modality, EUS guided biliary drainage, endoscopic radiofrequency ablation or photodynamic therapy (PDT). Percutaneous biliary drainage (PTBD) is also an approach used for palliation. It is generally used for segmental biliary obstruction due to tumors in the intra-hepatic bile ducts where endoscopic therapy may not be feasible or in selected patients with hilar CCAs. A study by Lee et al. ${ }^{[63]}$ evaluated outcomes for PTBD and endoscopic drainage for various types of Bismuth classification lesion. For type I and II lesions, there was no difference in the stent patency rates between both the groups for metal stent placement using either method. The best results were seen with endoscopic drainage in Bismuth type III lesions and PTBD for Bismuth type IV lesions ${ }^{[63]}$. Several studies have been performed comparing these two techniques of biliary drainage, including meta-analyses and results have shown that both techniques are 


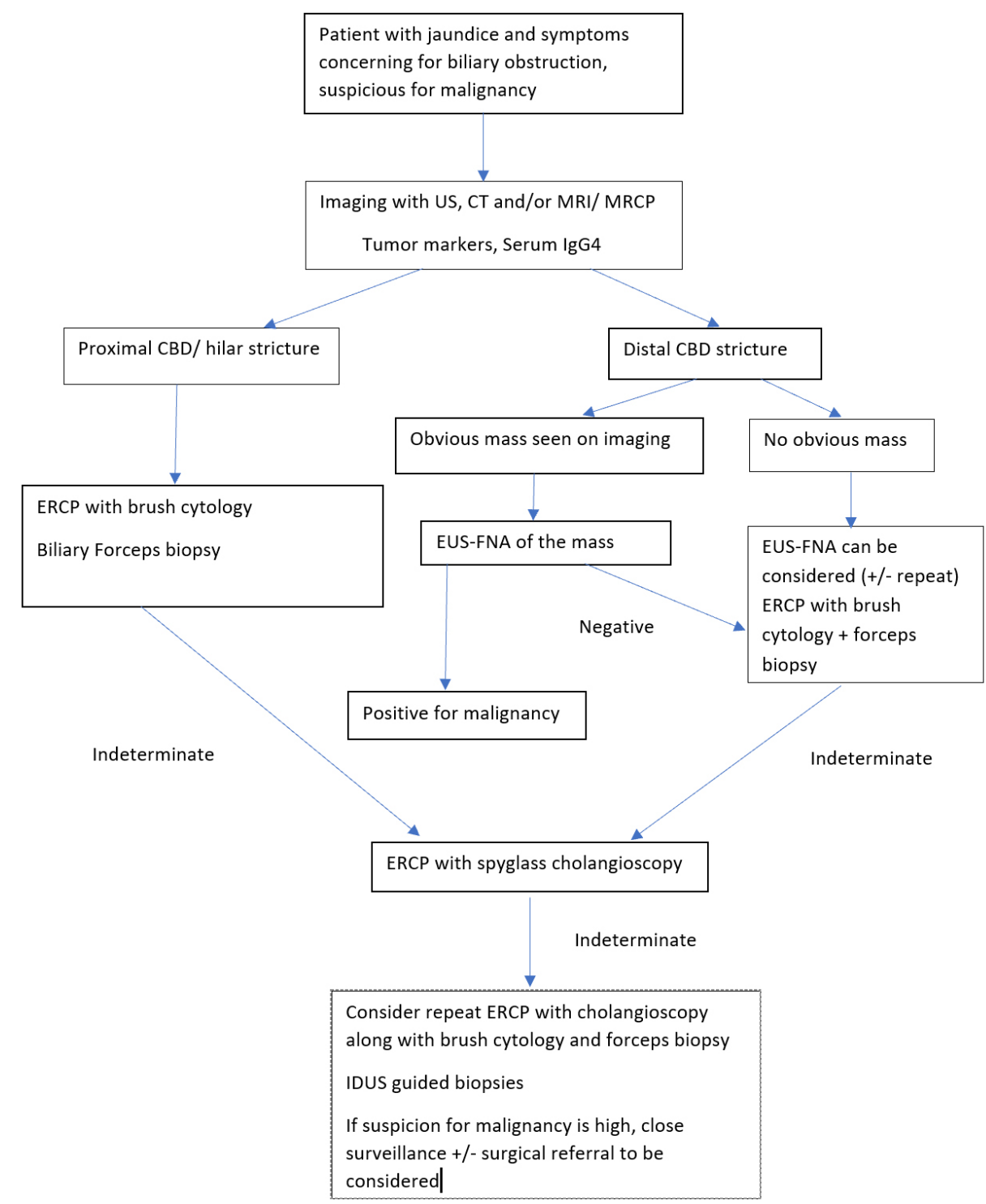

Figure 4. Diagnostic algorithm for malignant biliary stricture. US: Ultrasonography; CT: computed tomography; MRI/ MRCP: magnetic resonance imaging/magnetic resonance cholangiopancreatography; CBD: common bile duct; ERCP: endoscopic retrograde cholangiopancreatography; EUS: endoscopic ultrasound; FNA: fine needle aspiration; IDUS: intraductal ultrasound.

comparable in efficacy with certain advantages to each technique, but lesser morbidity and patient comfort with endoscopic drainage. PTBD is generally reserved when endoscopic biliary drainage fails ${ }^{[64]}$.

\section{ERCP stenting}

Endoscopic stenting has shown to be superior to surgical decompression with a bypass with less morbidity and mortality in multiple studies, but the surgical bypass is more durable as endoscopic drainage has a higher risk of biliary obstruction requiring repeat procedures ${ }^{[65,66]}$. Decompression with stenting is performed with ERCP and placement of a metal or plastic stent. In general, self-expandable metal stents (SEMS) are primarily used for decompression in MBO. Several studies have shown a lower rate of stent dysfunction and lower re-intervention rates with SEMS, mainly for extrahepatic tumors with strictures ${ }^{[67,68]}$. A meta-analysis by Zorrón Pu et al. ${ }^{[69]}$ showed stent dysfunction rates of $22 \%$ for SEMS compared to $47 \%$ for plastic stents with a stent patency duration of 250 days in comparison to 124 days with plastic stents. Moole 
et al. ${ }^{[70]}$ in their meta-analysis showed the median stent patency duration to be 167.7 days for SEMS while only 73.3 days for plastic stents, with lower rates of cholangitis in SEMS. Sangchan et al. ${ }^{[7]}$ in their RCT demonstrated a survival benefit for patients with SEMS compared to plastic stents but other studies have shown mixed results. Thus, the consensus is the use of SEMS for MBO, especially for distal strictures. The role of plastic stents for distal MBO is typically considered in patients with a life expectancy of fewer than 3 months.

\section{Type of SEMS}

Biliary SEMS come in diameters of 6,8 and $10 \mathrm{~mm}$ with lengths from 4 to $10 \mathrm{~cm}$. They can be of 3 types: fully covered (FCSEMS), partially covered (PCSEMS) or uncovered (USEMS). These stents are made from various materials and can be present with or without anti-migration valves and anti-reflux mechanisms ${ }^{[72]}$. They each have their own set of advantages and disadvantages. Generally, FCSEMS are more expensive and have higher rates of migration and reflux of duodenal contents, but they are easily removable ${ }^{[73]}$. They have also demonstrated higher rates of cholecystitis if the stent is placed across the cystic duct ${ }^{[74]}$. In comparison, USEMS have higher rates of tissue ingrowth and difficult to remove but have lower rates of migration. Both have comparable patency rates. The choice of SEMS in patients depends primarily on the level of biliary obstruction, distal $\mathrm{MBO}$ vs. proximal $\mathrm{MBO}$ due to hilar strictures, and whether removability may be important (e.g., indeterminate strictures).

For distal unresectable MBO, FCSEMS or UCSEMS are the primary options. Several studies have been performed comparing these two stents with conflicting results. Lee et al. ${ }^{[75]}$ in their retrospective study showed a higher rate of tissue ingrowth with obstruction in USEMS ( $76 \% v s .9 \%)$ but stent migration was more common in FCSEMS (36\% vs. $2 \%$ ). In contrast, Conio et al. ${ }^{[76]}$ in their RCT of 158 patients found higher rates of stent migration as well as stent occlusion in FCSEMS. Majmudar et al. ${ }^{[77]}$ demonstrated higher rates of cholecystitis by $15 \%$ for FCSEMS when compared to USEMS but another study by Isayama et al. ${ }^{[73]}$ showed no statistically significant difference between the two stents for cholecystitis in distal MBO. Thus, there is no consensus on the ideal type of stent to be used for distal MBO. The choice of stents should be individualized for every patient, depending on other clinical factors, life expectancy, possible need for removal and plan for chemoradiation.

For malignant hilar strictures, the choice of stents are either plastic or USEMS. Plastic stents are generally preferred for palliative stenting to relieve the biliary obstruction. FCSEMS are generally not preferred as they can cause blockage of the contralateral intrahepatic duct system. Several studies have investigated unilateral (left or the right duct system) or bilateral stenting. De Palma et al. ${ }^{[78]}$ in their RCT of 157 patients with hilar obstruction, comparing unilateral and bilateral stenting, demonstrated superior stent insertion rates with unilateral stenting $(88.6 \% v$ v. $76.9 \%, P=0.04)$ and higher complication rates with bilateral stenting (26.9\% vs. $18.9 \%, P=0.03$ ) on intention-to-treat analysis. A meta-analysis by Aghaie Meybodi et al. ${ }^{[79]}$ of 1300 patients with hilar strictures demonstrated comparable efficacy and safety for unilateral and bilateral stenting. Although in theory, bilateral stenting would make sense in draining more volume of the liver, studies have not shown the difference in survival, efficacy or complication rates between these two techniques. The principle of biliary stenting is to aim for drainage of at least $50 \%$ of the volume of the liver as studies have demonstrated a decreased risk of cholangitis and improved survival with it. Obtaining imaging prior to and after biliary stenting may provide information on the effective liver volume that is drained.

\section{Radiofrequency ablation}

Radiofrequency ablation (RFA) involves the administration of thermal energy to the malignant tumor causing tissue destruction with necrosis. The indications for the use of RFA are primarily focused on 
relieving obstruction of the bile duct and tissue ingrowth in the SEMS ${ }^{[80]}$. The technique involves advancing the catheter over a guidewire towards the target site. There are two catheters primarily used for this purpose: Habib Endo Bipolar Radiofrequency ablation catheter (Boston Scientific, USA) and Endoluminal Radiofrequency Ablation (Taewoong Medical, South Korea). Case series have reported improved survival and stent patency rates in patients who had RFA followed by SEMS in comparison to only SEMS. Increased incidence of adverse events such as cholangitis, pancreatitis and cholecystitis have been noted ${ }^{[81]}$. There is currently a need for RCTs to demonstrate survival benefits with RFA.

\section{Photodynamic therapy}

PDT has been described as an endobiliary treatment for CCA, mainly hilar CCA. The treatment consists of injection of a photosensitizing substance combined with irradiation of a laser at a specific wavelength ${ }^{[82]}$. This results in necrosis of the tumor cells by causing a disturbance in the vasculature and release of cytotoxic enzymes from lysosomes causing degradation of cell membranes. Cheon et al. ${ }^{[83]}$ in their nonrandomized prospective study compared patients undergoing PDT and stenting with those undergoing only biliary stenting for drainage. The median survival duration was longer in the PDT group compared to stenting-only group (588 days vs. 288 days, $P=0.01)^{[83]}$. There are published RCTs comparing PDT plus stenting with biliary stenting only. Ortner et al. ${ }^{[84]}$ in their study on non-resectable CCA, demonstrated a mortality benefit (median of 493 days vs. 98 days, $P<0.01$ ) with improvement in quality of life. Zoepf et al. ${ }^{\left[{ }^{[5]}\right]}$ in their RCT of 32 patients with bile duct cancer, demonstrated a longer duration of survival (21 months $v s .7$ months, $P=0.01)$ in the PDT group, but there were also higher rates of post-intervention cholangitis. Reports of bacterial cholangitis, liver abscesses and photo-toxicity to the skin ranging from $0 \%$ $25 \%$ have been published in clinical studies. One major limitation of PDT is its availability, being restricted only to large tertiary care centers, and phototoxicity to the skin and eyes. PDT has demonstrated good efficacy by the destruction of superficial layers of the bile duct tumors up to $5 \mathrm{~mm}$ with significantly less efficacy when tumor extension is beyond 7 to $9 \mathrm{~mm}^{\text {depth }}{ }^{[86]}$. Currently, the indications for PDT are sclerosing variant or superficial spreading type without mass variants of CCA without any distant or nodal metastasis. Factors associated with the survival of patients have been studied for PDT. The presence of lower serum albumin pre-treatment, visible mass on imaging and longer duration between diagnosis and PDT treatment are associated with poorer survival rates while lower pre-treatment bilirubin level and multiple PDT treatment sessions have demonstrated improved survival rates ${ }^{[87,88]}$.

\section{EUS guided biliary drainage}

When ERCP-guided biliary stenting failed, PTBD used to be the alternative treatment of choice. The advancement in the field of interventional EUS has provided another approach for internal biliary drainage. There are three different techniques for biliary drainage with EUS: (1) drainage of the intrahepatic ducts by hepatico-gastrostomy (HGS); (2) drainage of the extrahepatic CBD by choledocho-duodenostomy (CDS); and (3) EUS guided rendezvous procedure. In hepatico-gastrostomy, drainage is achieved by accessing a dilated biliary radical mainly in the left hepatic duct system followed by dilation of the tract and placement of a FCSEMS from the liver ducts to the gastric lumen ${ }^{[89]}$. In CDS, access to the CBD is achieved from the duodenal bulb followed by placement of a FCSEMS ${ }^{[90]}$. Drainage can also be achieved by placement of a metal stent in the gall bladder through the gastric antrum or duodenal bulb, if the cystic duct is patent ${ }^{[91]}$. The rendezvous procedure involves placement of a guidewire with the help of EUS guided access to the $\mathrm{CBD}$ and through the papilla, and papillary cannulation achieved with the help of the duodenoscope over or next to the guidewire. Both RCT data and meta-analyses have shown no difference in efficacy or safety comparing HGS and CDS and the choice of approach should depend on the patient's anatomy ${ }^{[92,93]}$. Recent studies have shown EUS-BD to be a superior option when compared to PTBD with lower rates of complications $^{[94]}$. 


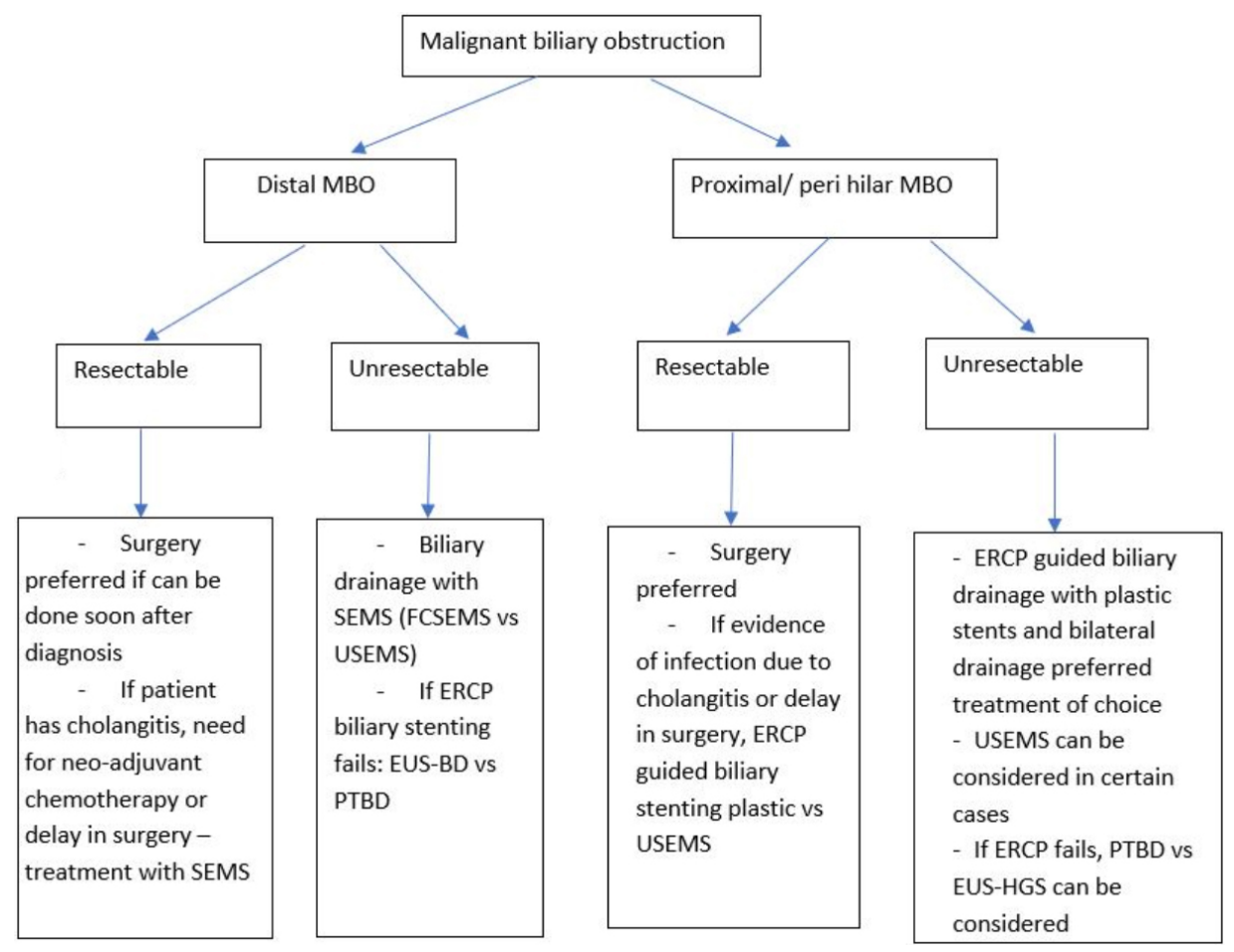

Figure 5. Treatment algorithm for management of malignant biliary obstruction. MBO: Malignant biliary obstruction; SEMS: selfexpanding metal stents; FCSEMS: fully covered self-expanding metal stents; USEMS: uncovered self-expanding metal stents; ERCP: endoscopic retrograde cholangiopancreatography; EUS: endoscopic ultrasound; BD: biliary drainage; PTBD: percutaneous transhepatic biliary drainage; HGS: hepaticogastrostomy.

\section{CONCLUSION}

A diagnosis of biliary malignancy should be pursued in patients demonstrating features of biliary obstruction and elevated liver enzymes in the appropriate clinical setting. The diagnostic algorithm involves obtaining tumor markers and imaging for evaluation of the biliary tract prior to tissue sampling with endoscopic techniques - EUS or ERCP. ERCP-guided brushings and forceps biopsies are the most common modality for diagnosis, but cholangioscopy guided direct biopsies can be obtained for indeterminate biliary strictures with prior inconclusive ERCPs. Treatment is mainly aimed at biliary drainage with trans-papillary stenting in unresectable cancers as a palliative measure, with metal stents generally preferred for distal cancers and plastic stents for more proximal tumors. For resectable cancers, up-front surgery is generally preferred unless it is delayed for neo-adjuvant chemotherapy or in patients with cholangitis, in which case ERCP with stenting should be performed [Figure 5]. Among SEMS, there are no data to demonstrate the superiority of one type over the other and hence decisions should be individualized to the patient. Recent advances in interventional EUS can help with both diagnoses and for biliary drainage in patients with failed ERCP or with inaccessible papilla. Despite the significant progress in this field, there are still some deficiencies that need to be addressed and further research with RCTs is needed.

\section{DECLARATIONS}

\section{Authors' contributions}

Conception and design, data acquisition, drafting of manuscript, revision of manuscript: Thoguluva Chandrasekar V

Conception and design, critical review, revision of manuscript: Faigel D 


\section{Availability of data and material}

Not applicable.

\section{Financial support and sponsorship}

None.

\section{Conflicts of interest}

Both authors declared that there are no conflicts of interest.

\section{Ethical approval and consent to participate}

Not applicable.

\section{Consent for publication}

Not applicable.

\section{Copyright}

(c) The Author(s) 2021.

\section{REFERENCES}

1. Bismuth H, Nakache R, Diamond T. Management strategies in resection for hilar cholangiocarcinoma. Ann Surg 1992;215:31-8. DOI PubMed PMC

2. Ebata T, Kosuge T, Hirano S, et al. Proposal to modify the International Union Against Cancer staging system for perihilar cholangiocarcinomas. Br J Surg 2014;101:79-88. DOI PubMed

3. Saha SK, Zhu AX, Fuchs CS, Brooks GA. Forty-year trends in cholangiocarcinoma incidence in the U.S.: intrahepatic disease on the rise. Oncologist 2016;21:594-9. DOI PubMed PMC

4. Bergquist A, von Seth E. Epidemiology of cholangiocarcinoma. Best Pract Res Clin Gastroenterol 2015;29:221-32. DOI PubMed

5. Tyson GL, El-Serag HB. Risk factors for cholangiocarcinoma. Hepatology 2011;54:173-84. DOI PubMed PMC

6. Singh A, Gelrud A, Agarwal B. Biliary strictures: diagnostic considerations and approach. Gastroenterol Rep (Oxf) 2015;3:22-31. DOI PubMed PMC

7. Albu S, Tanţău M, Spârchez Z, et al. Diagnosis and treatment of extrahepatic cholangiocarcinoma: results in a series of 124 patients. Rom J Gastroenterol 2005;14:33-6. PubMed

8. Choi SH, Han JK, Lee JM, et al. Differentiating malignant from benign common bile duct stricture with multiphasic helical CT. Radiology 2005;236:178-83. DOI PubMed

9. Ruys AT, Ven Beem BE, Engelbrecht MRW, et al. Radiological staging in patients with hilar cholangiocarcinoma: a systematic review and meta-analysis. Br J Radiol 2012;85:1255-62. DOI

10. Zhang H, Zhu J, Ke F, et al. Radiological imaging for assessing the respectability of Hilar cholangiocarcinoma: a systematic review and meta-analysis. Biomed Res Int 2015;2015:497942. DOI PubMed PMC

11. Vanderveen KA, Hussain HK. Magnetic resonance imaging of cholangiocarcinoma. Cancer Imaging 2004;4:104-15. DOI PubMed PMC

12. Yeh TS, Jan YY, Tseng JH, et al. Malignant perihilar biliary obstruction: magnetic resonance cholangiopancreatographic findings. Am J Gastroenterol 2000;95:432-40. DOI PubMed

13. Elias Y, Mariano AT Jr, Lu Y. Detection of primary malignancy and metastases with FDG PET/CT in patients with cholangiocarcinomas: lesion-based comparison with contrast enhanced CT. World J Nucl Med 2016;15:161-6. DOI PubMed PMC

14. Corvera CU, Blumgart LH, Akhurst T, et al. 18F-fluorodeoxyglucose positron emission tomography influences management decisions in patients with biliary cancer. $J$ Am Coll Surg 2008;206:57-65. DOI PubMed

15. Patel AH, Harnois DM, Klee GG, LaRusso NF, Gores GJ. The utility of CA 19-9 in the diagnoses of cholangiocarcinoma in patients without primary sclerosing cholangitis. Am J Gastroenterol 2000;95:204-7. DOI PubMed

16. Malaguarnera G, Paladina I, Giordano M, Malaguarnera M, Bertino G, Berretta M. Serum markers of intrahepatic cholangiocarcinoma. Dis Markers 2013;34:219-28. DOI PubMed PMC

17. Kim HJ, Kim MH, Myung SJ, et al. A new strategy for the application of CA19-9 in the differentiation of pancreaticobiliary cancer: analysis using a receiver operating characteristic curve. Am J Gastroenterol 1999;94:1941-6. DOI PubMed

18. Ramage JK, Donaghy A, Farrant J, Iorns R, Williams R. Serum tumor markers for the diagnosis of cholangiocarcinoma in primary sclerosing cholangitis. Gastroenterology 1995;108:865-9. DOI PubMed

19. Alvarez Herrero L, Curvers WL, van Vilsteren FG, et al. Validation of the Prague C\&M classification of Barrett's esophagus in clinical practice. Endoscopy 2013;45:876-82. DOI PubMed

20. Vedeld HM, Folseraas T, Lind GE. Detecting cholangiocarcinoma in patients with primary sclerosing cholangitis - The promise of DNA methylation and molecular biomarkers. JHEP Rep 2020;2:100143. DOI PubMed PMC 
21. Levy C, Lymp J, Angulo P, Gores GJ, Larusso N, Lindor KD. The value of serum CA 19-9 in predicting cholangiocarcinomas in patients with primary sclerosing cholangitis. Dig Dis Sci 2005;50:1734-40. DOI PubMed

22. Park HS, Lee JM, Choi JY, et al. Preoperative evaluation of bile duct cancer: MRI combined with MR cholangiopancreatography versus MDCT with direct cholangiography. AJR Am J Roentgenol 2008;190:396-405. DOI PubMed

23. Park MS, Kim TK, Kim KW, et al. Differentiation of extrahepatic bile duct cholangiocarcinoma from benign stricture: findings at MRCP versus ERCP. Radiology 2004;233:234-40. DOI PubMed

24. Furmanczyk PS, Grieco VS, Agoff SN. Biliary brush cytology and the detection of cholangiocarcinoma in primary sclerosing cholangitis: evaluation of specific cytomorphologic features and CA19-9 levels. Am J Clin Pathol 2005;124:355-60. DOI PubMed

25. Kurzawinski TR, Deery A, Dooley JS, Dick R, Hobbs KE, Davidson BR. A prospective study of biliary cytology in 100 patients with bile duct strictures. Hepatology 1993;18:1399-403. PubMed

26. Burnett AS, Calvert TJ, Chokshi RJ. Sensitivity of endoscopic retrograde cholangiopancreatography standard cytology: 10-y review of the literature. J Surg Res 2013;184:304-11. DOI PubMed

27. Kushnir VM, Mullady DK, Das K, et al. The diagnostic yield of malignancy comparing cytology, FISH, and molecular analysis of cell free cytology brush supernatant in patients with biliary strictures undergoing endoscopic retrograde cholangiography (ERC): a prospective study. J Clin Gastroenterol 2019;53:686-92. DOI PubMed PMC

28. Dudley JC, Zheng Z, McDonald T, et al. Next-Generation Sequencing and Fluorescence in Situ Hybridization Have Comparable Performance Characteristics in the Analysis of Pancreaticobiliary Brushings for Malignancy. J Mol Diagn 2016;18:124-30. DOI

29. Sugimoto S, Matsubayashi H, Kimura H, et al. Diagnosis of bile duct cancer by bile cytology: usefulness of post-brushing biliary lavage fluid. Endosc Int Open 2015;3:E323-8. DOI PubMed PMC

30. Tamada K, Tomiyama T, Wada S, et al. Endoscopic transpapillary bile duct biopsy with the combination of intraductal ultrasonography in the diagnosis of biliary strictures. Gut 2002;50:326-31. DOI PubMed PMC

31. Sugiyama M, Atomi Y, Wada N, Kuroda A, Muto T. Endoscopic transpapillary bile duct biopsy without sphincterotomy for diagnosing biliary strictures: a prospective comparative study with bile and brush cytology. Am J Gastroenterol 1996;91:465-7. PubMed

32. Chen WM, Wei KL, Chen YS, et al. Transpapillary biliary biopsy for malignant biliary strictures: comparison between cholangiocarcinoma and pancreatic cancer. World J Surg Oncol 2016;14:140. DOI PubMed PMC

33. Navaneethan U, Njei B, Lourdusamy V, Konjeti R, Vargo JJ, Parsi MA. Comparative effectiveness of biliary brush cytology and intraductal biopsy for detection of malignant biliary strictures: a systematic review and meta-analysis. Gastrointest Endosc 2015;81:168-76. DOI PubMed PMC

34. Sun B, Hu B. The role of intraductal ultrasonography in pancreatobiliary diseases. Endosc Ultrasound 2016;5:291-9. DOI PubMed PMC

35. Meister T, Heinzow HS, Woestmeyer C, et al. Intraductal ultrasound substantiates diagnostics of bile duct strictures of uncertain etiology. World J Gastroenterol 2013;19:874-81. DOI PubMed PMC

36. Tamada K, Ueno N, Tomiyama T, et al. Characterization of biliary strictures using intraductal ultrasonography: comparison with percutaneous cholangioscopic biopsy. Gastrointestinal Endoscopy 1998;47:341-9. DOI PubMed

37. Tamada K, Ido K, Ueno N, Kimura K, Ichiyama M, Tomiyama T. Preoperative staging of extrahepatic bile duct cancer with intraductal ultrasonography. Am J Gastroenterol 1995;90:239-46. PubMed

38. Kim HS, Moon JH, Lee YN, et al. Prospective comparison of intraductal ultrasonography-guided transpapillary biopsy and conventional biopsy on fluoroscopy in suspected malignant biliary strictures. Gut Liver 2018;12:463-70. DOI PubMed PMC

39. Ho M. The usefulness of IDUS-guided transpapillary bile duct biopsy for the diagnosis of malignant biliary strictures. Endoscopy 2011;43:A53. DOI

40. Conway JD, Mishra G. The role of endoscopic ultrasound in biliary strictures. Curr Gastroenterol Rep 2008;10:157-62. DOI PubMed

41. Garrow D, Miller S, Sinha D, et al. Endoscopic ultrasound: a meta-analysis of test performance in suspected biliary obstruction. Clin Gastroenterol Hepatol 2007;5:616-23. DOI PubMed

42. Topazian M. Endoscopic ultrasonography in the evaluation of indeterminate biliary strictures. Clin Endosc 2012;45:328-30. DOI PubMed PMC

43. Onda S, Ogura T, Kurisu Y, et al. EUS-guided FNA for biliary disease as first-line modality to obtain histological evidence. Therap Adv Gastroenterol 2016;9:302-12. DOI PubMed PMC

44. De Moura DTH, Moura EGH, Bernardo WM, et al. Endoscopic retrograde cholangiopancreatography versus endoscopic ultrasound for tissue diagnosis of malignant biliary stricture: Systematic review and meta-analysis. Endosc Ultrasound 2018;7:10-9. DOI PubMed PMC

45. Weilert F, Bhat YM, Binmoeller KF, et al. EUS-FNA is superior to ERCP-based tissue sampling in suspected malignant biliary obstruction: results of a prospective, single-blind, comparative study. Gastrointest Endosc 2014;80:97-104. DOI PubMed

46. Jo JH, Cho CM, Jun JH, et al; Research Group for Endoscopic Ultrasonography in KSGE. Same-session endoscopic ultrasound-guided fine needle aspiration and endoscopic retrograde cholangiopancreatography-based tissue sampling in suspected malignant biliary obstruction: a multicenter experience. J Gastroenterol Hepatol 2019;34:799-805. DOI PubMed

47. Heimbach JK, Sanchez W, Rosen CB, Gores GJ. Trans-peritoneal fine needle aspiration biopsy of hilar cholangiocarcinoma is associated with disease dissemination. HPB (Oxford) 2011;13:356-60. DOI PubMed PMC

48. Micames C, Jowell PS, White R, et al. Lower frequency of peritoneal carcinomatosis in patients with pancreatic cancer diagnosed by EUS-guided FNA vs. percutaneous FNA. Gastrointest Endosc 2003;58:690-5. DOI PubMed

49. Chen YK, Pleskow DK. SpyGlass single-operator peroral cholangiopancreatoscopy system for the diagnosis and therapy of bile-duct 
disorders: a clinical feasibility study (with video). Gastrointest Endosc 2007;65:832-41. DOI PubMed

50. Pereira P, Santos S, Morais R, et al. Role of peroral cholangioscopy for diagnosis and staging of biliary tumors. Dig Dis 2020;38:43140. DOI PubMed

51. Shah RJ, Raijman I, Brauer B, Gumustop B, Pleskow DK. Performance of a fully disposable, digital, single-operator cholangiopancreatoscope. Endoscopy 2017;49:651-8. DOI PubMed

52. Urban O, Evinová E, Fojtík P, et al. Digital cholangioscopy: the diagnostic yield and impact on management of patients with biliary stricture. Scand J Gastroenterol 2018;53:1364-7. DOI PubMed

53. Varadarajalu S, Bang JY, Hasan MK, et al. Improving the diagnostic yield of single-operator cholangioscopy-guided biopsy of indeterminate biliary strictures: ROSE to the rescue? Gastrointest Endosc 2016;84:681-7. DOI

54. Navaneethan U, Hasan MK, Kommaraju K, et al. Digital, single-operator cholangiopancreatoscopy in the diagnosis and management of pancreatobiliary disorders: a multicenter clinical experience (with video). Gastrointest Endosc 2016;84:649-55. DOI PubMed

55. Bang JY, Navaneethan U, Hasan M, Sutton B, Hawes R, Varadarajulu S. Optimizing outcomes of single-operator cholangioscopyguided biopsies based on a randomized trial. Clin Gastroenterol Hepatol 2020;18:441-8.e1. DOI PubMed

56. Korrapati P, Ciolino J, Wani S, et al. The efficacy of peroral cholangioscopy for difficult bile duct stones and indeterminate strictures: a systematic review and meta-analysis. Endosc Int Open 2016;4:E263-75. DOI PubMed PMC

57. Strasberg SM, Gao F, Sanford D, et al. Jaundice: an important, poorly recognized risk factor for diminished survival in patients with adenocarcinoma of the head of the pancreas. HPB (Oxford) 2014;16:150-6. DOI PubMed PMC

58. van der Gaag NA, Rauws EA, van Eijck CH, et al. Preoperative biliary drainage for cancer of the head of the pancreas. N Engl J Med 2010;362:129-37. DOI PubMed

59. Neuhaus H. Preoperative biliary drainage in hilar cholangiocarcinoma: when and how? Endosc Int Open 2020;8:E211-3. DOI PubMed PMC

60. Coelen RJS, Roos E, Wiggers JK, et al. Endoscopic versus percutaneous biliary drainage in patients with resectable perihilar cholangiocarcinoma: a multicentre, randomised controlled trial. Lancet Gastroenterol Hepatol 2018;3:681-90. DOI PubMed

61. Fang Y, Gurusamy KS, Wang Q, et al. Meta-analysis of randomized clinical trials on safety and efficacy of biliary drainage before surgery for obstructive jaundice. Br J Surg 2013;100:1589-96. DOI PubMed

62. Baron TH, Mallery J, Hirota WK, et al. The role of endoscopy in the evaluation and treatment of patients with pancreaticobiliary malignancy. Gastrointest Endosc 2003;58:643-9. DOI PubMed

63. Lee SH, Park JK, Yoon WJ, et al. Optimal biliary drainage for inoperable Klatskin's tumor based on Bismuth type. World $J$ Gastroenterol 2007;13:3948-55. DOI PubMed PMC

64. Duan F, Cui L, Bai Y, Li X, Yan J, Liu X. Comparison of efficacy and complications of endoscopic and percutaneous biliary drainage in malignant obstructive jaundice: a systematic review and meta-analysis. Cancer Imaging 2017;17:27. DOI PubMed PMC

65. Lima SLAD, Bustamante FAC, Moura EGHD, et al. Endoscopic palliative treatment versus surgical bypass in malignant low bile duct obstruction: a systematic review and meta-analysis. Int J Hepatobiliary Pancreat Dis 2015;5:35. DOI

66. Arshad SA, Phuoc VH. Surgical palliation of biliary obstruction: bypass in the era of drainage. J Surg Oncol 2019;120:65-6. DOI PubMed

67. Yoon WJ, Ryu JK, Yang KY, et al. A comparison of metal and plastic stents for the relief of jaundice in unresectable malignant biliary obstruction in Korea: an emphasis on cost-effectiveness in a country with a low ERCP cost. Gastrointest Endosc 2009;70:284-9. DOI PubMed

68. Biddlestone LR, Barham CP, Wilkinson SP, Barr H, Shepherd NA. The histopathology of treated Barrett's esophagus: squamous reepithelialization after acid suppression and laser and photodynamic therapy. Am J Surg Pathol 1998;22:239-45. DOI PubMed

69. Zorrón Pu L, de Moura EG, Bernardo WM, et al. Endoscopic stenting for inoperable malignant biliary obstruction: a systematic review and meta-analysis. World J Gastroenterol 2015;21:13374-85. DOI PubMed PMC

70. Moole H, Jaeger A, Cashman M, et al. Are self-expandable metal stents superior to plastic stents in palliating malignant distal biliary strictures? Med J Armed Forces India 2017;73:42-8. DOI PubMed PMC

71. Sangchan A, Kongkasame W, Pugkhem A, Jenwitheesuk K, Mairiang P. Efficacy of metal and plastic stents in unresectable complex hilar cholangiocarcinoma: a randomized controlled trial. Gastrointest Endosc 2012;76:93-9. DOI PubMed

72. Nam HS, Kang DH. Current status of biliary metal stents. Clin Endosc 2016;49:124-30. DOI PubMed PMC

73. Isayama H, Komatsu Y, Tsujino T, et al. A prospective randomised study of "covered" versus "uncovered" diamond stents for the management of distal malignant biliary obstruction. Gut 2004;53:729-34. DOI PubMed PMC

74. Jang S, Stevens T, Parsi M, et al. Association of covered metallic stents with cholecystitis and stent migration in malignant biliary stricture. Gastrointest Endosc 2018;87:1061-70. DOI PubMed

75. Lee JH, Krishna SG, Singh A, et al. Comparison of the utility of covered metal stents versus uncovered metal stents in the management of malignant biliary strictures in 749 patients. Gastrointest Endosc 2013;78:312-24. DOI PubMed

76. Conio M, Mangiavillano B, Caruso A, et al. Covered versus uncovered self-expandable metal stent for palliation of primary malignant extrahepatic biliary strictures: a randomized multicenter study. Gastrointest Endosc 2018;88:283-91.e3. DOI PubMed

77. Majmudar K, Murad F. Fully-covered self-expandable metal stents may increase the risk of cholecystitis in patients with intact gallbladders compared to uncovered self-expandable metal stents when placed for malignant biliary obstruction. Am J Gastroenterol. 2018;113:S6. DOI

78. Palma GD, Galloro G, Siciliano S, Iovino P, Catanzano C. Unilateral versus bilateral endoscopic hepatic duct drainage in patients with malignant hilar biliary obstruction: results of a prospective, randomized, and controlled study. Gastrointest Endosc 2001;53:547-53. DOI PubMed 
79. Aghaie Meybodi M, Shakoor D, Nanavati J, et al. Unilateral versus bilateral endoscopic stenting in patients with unresectable malignant hilar obstruction: a systematic review and meta-analysis. Endosc Int Open 2020;8:E281-90. DOI PubMed PMC

80. Dolak W, Schreiber F, Schwaighofer H, et al; Austrian Biliary RFA Study Group. Endoscopic radiofrequency ablation for malignant biliary obstruction: a nationwide retrospective study of 84 consecutive applications. Surg Endosc 2014;28:854-60. DOI PubMed

81. Sofi AA, Khan MA, Das A, et al. Radiofrequency ablation combined with biliary stent placement versus stent placement alone for malignant biliary strictures: a systematic review and meta-analysis. Gastrointest Endosc 2018;87:944-51.e1. DOI PubMed

82. Ortner MA. Photodynamic therapy for cholangiocarcinoma. Lasers Surg Med 2011:43:776-80. DOI PubMed

83. Cheon YK, Cho YD, Baek SH, et al. Comparison of survival of advanced hilar cholangiocarcinoma after biliary drainage alone versus photodynamic therapy with external drainage. Korean J Gastroenterol 2004;44:280-7. PubMed

84. Ortner ME, Caca K, Berr F, et al. Successful photodynamic therapy for nonresectable cholangiocarcinoma: a randomized prospective study. Gastroenterology 2003;125:1355-63. DOI PubMed

85. Zoepf T, Jakobs R, Arnold JC, Apel D, Riemann JF. Palliation of nonresectable bile duct cancer: improved survival after photodynamic therapy. Am J Gastroenterol 2005;100:2426-30. DOI PubMed

86. Wiedmann M, Berr F, Schiefke I, et al. Photodynamic therapy in patients with non-resectable hilar cholangiocarcinoma: 5-year followup of a prospective phase II study. Gastrointest Endosc 2004;60:68-75. DOI PubMed

87. Prasad GA, Wang KK, Baron TH, et al. Factors associated with increased survival after photodynamic therapy for cholangiocarcinoma. Clin Gastroenterol Hepatol 2007;5:743-8. DOI PubMed

88. Cheon YK, Lee TY, Lee SM, Yoon JY, Shim CS. Longterm outcome of photodynamic therapy compared with biliary stenting alone in patients with advanced hilar cholangiocarcinoma. HPB (Oxford) 2012;14:185-93. DOI PubMed PMC

89. Giovannini M. EUS-guided hepaticogastrostomy. Endosc Ultrasound 2019;8:S35-9. DOI PubMed PMC

90. Artifon EL, Perez-Miranda M. EUS-guided choledochoduodenostomy for malignant distal biliary obstruction palliation: an article review. Endosc Ultrasound 2012;1:2-7. DOI PubMed PMC

91. Baars JE, Kaffes AJ, Saxena P. EUS-guided biliary drainage: a comprehensive review of the literature. Endosc Ultrasound 2018;7:4-9. DOI PubMed PMC

92. Minaga K, Ogura T, Shiomi H, et al. Comparison of the efficacy and safety of endoscopic ultrasound-guided choledochoduodenostomy and hepaticogastrostomy for malignant distal biliary obstruction: multicenter, randomized, clinical trial. Dig Endosc 2019;31:575-82. DOI PubMed

93. Uemura RS, Khan MA, Otoch JP, Kahaleh M, Montero EF, Artifon ELA. EUS-guided choledochoduodenostomy versus hepaticogastrostomy: a systematic review and meta-analysis. J Clin Gastroenterol 2018;52:123-30. DOI PubMed

94. Moole H, Bechtold ML, Forcione D, Puli SR. A meta-analysis and systematic review: success of endoscopic ultrasound guided biliary stenting in patients with inoperable malignant biliary strictures and a failed ERCP. Medicine (Baltimore) 2017;96:e5154. DOI PubMed PMC 